\title{
Nursing Students: Untapped Resource for Running Computerized Patient Simulators
}

\author{
Starla Aragon \\ Amy Kotter \\ Patricia K. Ravert \\ Brigham Young University - Provo, patricia-ravert@byu.edu \\ Suzan E. Kardong-Edgren \\ Washington State University
}

Follow this and additional works at: https://scholarsarchive.byu.edu/facpub

Part of the Other Nursing Commons

\section{Original Publication Citation}

Aragon, S., Kotter, A., Ravert, P. K., \& Kardong-Edgren, S. E. (2011, January). Nursing students:

Untapped resource for running computerized patient simulators. Clinical Simulation in Nursing. 7(1), e25-e29.

\section{BYU ScholarsArchive Citation}

Aragon, Starla; Kotter, Amy; Ravert, Patricia K.; and Kardong-Edgren, Suzan E., "Nursing Students:

Untapped Resource for Running Computerized Patient Simulators" (2010). Faculty Publications. 5275.

https://scholarsarchive.byu.edu/facpub/5275

This Peer-Reviewed Article is brought to you for free and open access by BYU ScholarsArchive. It has been accepted for inclusion in Faculty Publications by an authorized administrator of BYU ScholarsArchive. For more information, please contact ellen_amatangelo@byu.edu. 


\title{
Nursing Students: Untapped Resource for Running Computerized Patient Simulators
}

\author{
Starla Aragon, RN, BS ${ }^{\mathrm{a}}$, Amy Kotter, RN, BS ${ }^{\mathrm{b}}$, Patricia K. Ravert, PhD, RN, CNE ${ }^{\mathrm{c} *}$, \\ Suzan E. Kardong-Edgren, PhD, RN ${ }^{d}$
}

${ }^{a}$ Primary Children's Medical Center, Salt Lake City, UT 84113, USA

${ }^{b}$ Cook Children's Medical Center, Fort Worth, TX 76104, USA

${ }^{c}$ Brigham Young University, College of Nursing, Provo, UT 84602, USA

${ }^{d}$ Washington State University, Spokane, WA 99210, USA
KEYWORDS
nursing;
education;
implementation;
simulation;
HFS;
HPS;
cost;
learning;
faculty;
anxiety;
technique;
critical thinking;
challenges;
technology;
students

\begin{abstract}
High-fidelity simulation (HFS) is sweeping the nation as a legitimate and exciting new resource for nursing educators. As with most new technologies, HFS is not without its difficulties. It can be a costly program to run and may also cause anxiety among the faculty required for implementation. There is a simple solution to help increase the ease of its implementation: using student workers. This article discusses how using students to help run the simulations can not only reduce overall cost and anxiety associated with this new technology but also increase learning among those participating in HFS.
\end{abstract}

\section{Cite this article:}

Aragon, S., Kotter, A., Ravert, P. K., \& Kardong-Edgren, S. E. (2011, January). Nursing students: Untapped resource for running computerized patient simulators. Clinical Simulation in Nursing, 7(1), e25-e29. doi: 10.1016/j.ecns.2010.01.006

(C) 2011 International Nursing Association for Clinical Simulation and Learning. Published by Elsevier Inc. All rights reserved.
The increasing adoption of simulation as a major teaching strategy across all of academia is significantly changing the work of teaching. Faculty member reactions to these rapid changes range from critical, antagonistic, and indifferent to favorable and enthusiastic (Nomdo, 2004). Simulation in nursing curricula in the United States is most likely in the early majority stage of Rogers's (2003) theory of innovation diffusion in terms of purchasing of equipment. However, it is more likely to be in the early adopter stage in terms of faculty

Corresponding author: patricia_ravert@byu.edu (P. K. Ravert). adoption and integration of the technology into a curriculum. Recent research indicates that money to purchase simulators is easier to garner than faculty buy-in, or the willingness to learn, run, and use simulation (Hanberg, 2008; Wendy Thompson, personal communication, June 2009). This reluctance is largely due to the perceived or real lack of time and resources needed to learn to run high-fidelity simulation (Bray, Schwartz, Weeks, \& Kardong-Edgren, 2009; Hanberg, 2008; Jones \& Hegge, 2008; King, Moseley, Hindenlang, \& Kuritz, 2008).

The average age of the nursing education workforce is greater than 50 (Hanberg, 2008), making nurse educators in 
general digital immigrants (Prensky, 2001) and potentially uncomfortable with rapidly changing technological advances. "Not all health care workers welcome computers into their sphere of practice, and anecdotally, many nurses feel apprehensive, or even fearful, when contemplating their use" (Toofany, 2006, p. 18). If faculty remain apprehensive about learning and using this technology, comfort levels necessary to fully implement the technology will not be established. As the technology level increases, faculty comfort levels decrease (Jones \& Hegge, 2008). This

Key Points
- Student workers can
enhance the learning
of those participating
in the simulation.
- Student workers can
decrease faculty anxi-
ety and therefore in-
crease faculty buy-in.
- Student workers help
reduce overall cost of
running a simulation
lab.
- Student workers can
allow faculty to focus
on student responses
rather than the simula-
tion technology.

creates a problem as it is necessary for comfort levels to increase for success to increase.

Faculty find the multitasking required of a lone simulation operator very challenging (KardongEdgren, Starkweather, \& Ward, 2008) and welcome a simulation operator so that they can focus on the student responses in the scenario. Faculty members report that if additional lab personnel were present to assist them, they would use high fidelity simulation (HFS) more frequently (King et al., 2008). This article proposes two possible solutions for some of the challenges associated with implementing simulation.

\section{The Brigham Young University Experience of Student Workers in Simulation}

Brigham Young University's (BYU's) college of nursing (CON) has been using HFS for the past 8 years. BYU uses both Medical Education Technologies and Gaumard highfidelity simulators. As the BYU simulation faculty members began developing and implementing HFS, they decided to use a model that involved students as part of the simulation staff. They have found student workers enhance student learning, reduce faculty anxiety, and reduce the overall cost of using simulation. Student workers are hired at an hourly wage during their 1st year in nursing school so they can be involved in running the simulation program for 1 to 2 years. Choosing student workers is quite simple. Those students who have shown enthusiasm for simulation in their first semester as participants are identified by current student workers and asked to interview for the position. The position is also opened up to others who may be equally interested and enthusiastic but were not specifically identified and asked to apply. Therefore, all first- and second-semester students are able to apply to be a student worker if they desire to do so. The applicants are then interviewed by the BYU nursing learning center supervisor or director. Those hired are chosen according to their schedule availability and commitment. Their commitment is shown through their understanding of how beneficial simulation can be as a learning tool, as well as their enjoyment of and ability to help younger students understand difficult concepts and think more critically. The recommendation of the current student workers is also taken into consideration. It is important that their school and personal schedule fits the current needs of the simulation program.

Brigham Young University's CON has three or four simulation workers employed at any given time. Most simulation workers average 5 to 10 hours of simulation work each week. As the student workers enters their final semester in nursing school, they begin training a first- or second-semester nursing student as their replacement. Therefore, it is important to hire new workers at least by midterm to be sure they are fully trained and comfortable with running simulations on their own for the next semester.

\section{Student Worker Roles}

Student workers perform a variety of tasks and roles in the simulation lab. Depending on the need of the scenario, one to two student workers participate in each scenario to help facilitate student learning. They are responsible for setting up and cleaning up, running the computer, acting as the voice of the patient and the health care provider, playing the role of family members, and providing additional teaching assistance.

\section{Setup}

Student workers are responsible for setting up and maintaining as realistic an environment as possible. They arrive at the simulation lab 15 and 30 minutes early in order to have the lab set up and ready before the student comes in the door. They are responsible for turning the simulator on and ensuring that all mechanical features are working properly. In the event that something is not working properly, the student workers are responsible for troubleshooting the problem and then contacting the supervising faculty member if they are unable to resolve the issue. Once the simulator is on, the student workers begin setting up the milieu, which includes the patient's clothing, hair, dressings, drains, scents, and so forth. They attempt to make the lab look and smell as much like a normal patient setting as possible. Having the student workers set up the scene makes it possible for the faculty to come in just before the scenario is to begin, which helps reduce overall cost. It is much less expensive to pay a student an hourly rate than it is to pay a faculty member. Having student workers set up the scene also allows faculty members to gather their thoughts in order to make teaching more effective.

\section{Cleanup}

The cleanup process is simply undoing the setup. Student workers put supplies away in the appropriate location and 
restock, allowing for quick turnaround the next time the scenario is used. Having student workers clean up the scene allows faculty to leave as soon as the scenario is finished, saving their time and the college's money. It also allows the faculty additional time to answer questions that students may have as a result of the scenario.

\section{Running the Computer}

Once the scenario has been opened and started on the computer, the student worker is responsible for advancing the scenario based on student actions. According to the interventions the participating students provide or don't provide, the student workers change the state of the patient to simulate improvement or worsening of the patient's condition. A reactive patient response makes the situation realistic and reinforces good actions and choices while discouraging poor choices. For example, when the students put oxygen on their patient, the oxygen saturation reading goes up. Likewise, if they forget to put oxygen on the patient, the oxygen saturation reading will drop. The students are able to learn more as they see the cause-and-effect relationship of their actions. The student worker continues to run the simulation until one of three things happen: Either the patient returns to a stable condition or dies, or the students run out of time.

Having student workers run the computer reduces the fears of faculty and allows the faculty more time to prompt, teach, and answer questions from the students. Because the same student workers run the same scenarios over and over again, when computer problems do arise, the student workers are able to respond without anxiety.

\section{Role-Playing}

Another responsibility of the student workers is to roleplay. For HFS to be as realistic as it can be, the patient must respond appropriately when addressed. When faculty members speak as the patient, we have found our students becoming confused about when they are supposed to be hearing the patient talking and when the faculty member is commenting about something. We have found that having student workers act as the patient's voice during simulations is less confusing for the participating students. Furthermore, having the patient's voice be completely independent of any other voice has made it easier for our students to treat the simulator as a real patient. In addition, having a student worker act as the voice allows faculty members to focus solely on teaching.

Student workers also act as the patient's health care provider. In each of our scenarios, participating students find themselves in a position that necessitates calling the health care provider on the phone. The student worker answers the phone call and responds as the health care provider, using a prepared script and asking the students questions if information is lacking. Then the students are given appropriate orders, which they carry out.
A few of our scenarios involve having the student workers act as a patient's family member. In these situations, we always have two student workers present. One runs the computer and acts as the patient while the other acts as the family member. Having student workers act in this capacity enables participating students to learn how to communicate more effectively with family members and how to ask important questions and obtain information necessary for appropriate care.

\section{Teaching Assistants}

The student workers also act as teaching assistants. They provide extra eyes and ears to help catch mistakes or clarify points. Quite often, participating students will be doing multiple things at one time and all will need help. Student workers jump in where needed to help teach and assist students. This help ranges from assisting with medication calculations to hanging intravenous fluid and to simple things such as teaching a new student how to use an injection device properly.

Oftentimes, the student workers are able to teach difficult concepts in a way that is understandable to the novice student. Sobral (1994) did a study with Brazilian medical students in which separate groups of students were taught the same material. One group, however, was taught by faculty and the other by senior students. Sobral found that those taught by students were not disadvantaged on "scores of problem solving and self-evaluation" when compared with their faculty-tutored peers (p. 284). Therefore, participating students can be greatly advantaged by having a peer teach in their lab. The students are able to get more one-on-one attention without being disadvantaged by incorrect or less than complete information.

\section{Benefits of Being a Student Worker}

The BYU CON has found that students participating in simulation and faculty are not the only people who benefit from this model of simulation. This model also benefits those hired as the student workers. It allows them to learn new concepts and ideas from the teaching faculty, as well as cement those ideas in their minds by teaching them to other students. Curl, Smith, Chisholm, Hamilton, and McGee (2007) have stated that "an additional benefit for the senior students working in the Skills Lab is an increased comfort level with skill competency through the additional laboratory experience received" (p. 195). Escovitz (1990) echoed this finding, stating that senior students benefit by being able to review and enhance their own skills.

Additionally, student workers have the opportunity to enhance their leadership and teaching abilities through the mentorship of younger nursing students. Escovitz (1990) cited this benefit by saying that learning how to teach is a valuable skill that can be acquired from teaching younger students. 
These added benefits continue as student workers enter the workforce. Student workers have commented that they feel more prepared and have found themselves advantaged more than their peer graduate nurses who were not student workers. Student workers have also commented that they are more at ease handling medical equipment and are more comfortable than their peers with recognition and treatment of abnormal findings.

Participating in the writing of scenarios has also provided student workers with added benefits. Writing the simulation helps student workers learn the pathophysiology more in depth. With deeper understanding of pathophysiology the student workers are able to better mentor the younger students. This practice of student-written and student-led scenarios has been used successfully at the University of Texas at Arlington.

\section{Student-Written, Student-Led Scenarios: An Experience at the University of Texas at Arlington}

A reserve army corpsman returned to nursing school after stepping out of a physical assessment course halfway through the semester for a tour of duty in Iraq. A year later he reentered our nursing program and began repeating the assessment course. To the faculty this appeared to be a waste of valuable assessment experience. We needed an appropriate simulation scenario for an end-of-course simulation experience. To capitalize on the skills of this experienced corpsman and another paramedic student in the course, faculty tested these two students early on the usual head-to-toe checkoff and skills portion of the lab experience for the course. The two were then tasked with writing the end-of-course scenario experience for the rest of the students in the course. All students had participated in assessment scenarios regularly during the course of the semester, and thus they were very comfortable with the simulation experience.

Learning to operate the simulator took these two students less than 10 minutes. Over several weeks, they wrote a scenario addressing changing level of consciousness, which was used as an ungraded final scenario in the physical assessment class. One of the student's wives recorded scripted answers to the questions the students anticipated would be asked during an assessment. These responses were turned into wave files on a PDA. The students writing the scenario anticipated almost all needed responses except a simple yes-no answer, necessitating the use of their own male voices to answer some questions.

They ran and debriefed this level-of-consciousness scenario for 98 fellow students during one day at the end of the semester. The scenario became known as the Knight-Sparks scenario (a combination of their last names). The scenarios were run simultaneously in a large divided room. Each student leader guided a clinical group of 10 students, accompanied by their clinical assessment faculty, through the scenario and debriefing. In each group, 5 students participated in various scenario roles, and 5 students watched and took notes.

Only one group of five students, out of all 10 groups, assessed the patient's pupils during the simulation. Lack of pupil assessment led to worsening symptoms of a subdural hematoma and sudden cardiac arrest, necessitating CPR. All students were extremely engaged during their scenarios. Those serving in observation roles found it hard not to intervene if they knew what was required.

The experience was rated as highly positive by all participants. Faculty learned for the first time what wave files were and how to use a PDA in a simulation. Faculty also gained a first-rate, reusable, student-designed scenario. Two students learned how to write and run a scenario. The army corpsman took his newfound simulation skills back to his unit to demonstrate the use of a simulator in medical field training. The other students in the class participated in a well-prepared, student-led scenario and debriefing session.

\section{Recommendations}

\section{Faculty}

To implement this model in your college, we suggest initially determining the availability of monies to fund student workers. If no college funds are readily available for use, look into obtaining a grant. Another option is starting a simulation club in which students can donate their time in exchange for the learning and growth associated with participating in and observing simulations.

\section{Students}

Seek out opportunities to participate in simulation, whether as a worker or as a participant. You will benefit greatly by increased knowledge of the pathophysiology involved in the scenarios you work with and a better ability to perform nursing tasks. Participate in writing scenarios: This is a perfect opportunity to learn and cement in your mind important concepts for patient care and pathophysiology.

Every college has the resources to run its simulation program with more ease. Students are the resource that needs to be tapped in order to promote this valuable resource for nursing instruction: high-fidelity simulation.

\section{References}

Bray, B., Schwartz, C., Weeks, D., \& Kardong-Edgren, S. (2009, July). Human patient simulation technology: Perceptions from a multidisciplinary sample of health educators. Clinical Simulation in Nursing, 5, e145e150. doi:10.1016/j.ecns.2009.02.002.

Curl, E. D., Smith, S., Chisholm, L., Hamilton, J., \& McGee, L. A. (2007). Multidimensional approaches to extending nurse faculty 
resources without testing faculty's patience. Education Innovations, 46(4), 193-195.

Escovitz, E. S. (1990). Using senior students as clinical teaching assistants. Academic Medicine: Journal of the Association of American Medical Colleges, 65(12), 733-734.

Hanberg, A. (2008). The diffusion of high fidelity simulation in nursing education: Barriers and recommendations for best practice. Greeley: Unpublished doctoral dissertation, University of Northern Colorado.

Jones, A., \& Hegge, M. (2008, July). Simulation and faculty time investment. Clinical Simulation in Nursing, 4(2). doi:10.1016/j.ecns.2008.06.003.

Kardong-Edgren, S., Starkweather, A., \& Ward, L. (2008). The integration of simulation into a clinical foundations of nursing course: Student and faculty perspectives. International Journal of Nursing Education Scholarship, 5(1). Article 26.
King, C. J., Moseley, S., Hindenlang, B., \& Kuritz, P. (2008). Limited use of the human patient simulator by nurse faculty: An intervention program designed to increase use. International Journal of Nursing Education Scholarship, 5(1). Article 12.

Nomdo, G. (2004). Collaborating within the "risk" zone: A critical reflection. Active Learning in Higher Education, 5(3), 205-216.

Prensky, M. (2001). Digital natives, digital immigrants. Retrieved February 1, 2010, from http://www.marcprensky.com/writing/Prensky\%20\%20Digital\%20Natives,\%20Digital\%20Immigrants\%20-\%20Part1.pdf

Rogers, E. M. (2003). Diffusion of innovations (5th ed.). New York: Free Press. Sobral, D. T. (1994). Peer tutoring and student outcomes in a problembased course. Medical Education, 28(4), 284-289.

Toofany, S. (2006). Nursing and information technology. Nursing Management, 13(7), 18-19. 